\title{
UTILIZAÇÃO DO KOBOTOOLBOX PARA CARACTERIZAÇÃO DAS UNIDADES DE SAÚDE DA REDE MUNICIPAL DE JATAÍ-GO, 2019
}

\section{USE OF THE KOBOTOOLBOX FOR CHACACTERIZATION OF THE HEALTH UNITS OF THE MUNICIPAL NETWORK OF JATAÍ-GO, 2019}

\begin{abstract}
Juliana Freitas Silva
Universidade Federal de Jataí, Programa de Pós-graduação em Geografia, Jataí, GO, Brasil juliana freitas@ufj.edu.br

Maria José Rodrigues

Universidade Federal de Jataí, Programa de Pós-graduação em Geografia, Jataí, GO, Brasil mariarodrigues@ufj.edu.br
\end{abstract}

Márcio Rodrigues Silva Universidade Federal de Jataí, Programa de Pós-graduação em Geografia, Jataí, GO, Brasil marciosilva@ufj.edu.br

\begin{abstract}
RESUMO
Os estabelecimentos públicos de saúde compõem a rede pública municipal de saúde das cidades, e para que eles desenvolvam um atendimento de qualidade, que permita o acesso da população, é de fundamental importância conhecer as características desses locais. Diante disso, o trabalho proposto tem por objetivo caracterizar os estabelecimentos públicos de saúde da cidade de Jataí - Goiás por meio do sistema KoBoToolbox, de modo a testar as ferramentas que ele possui para pesquisas na área da saúde. A proposta de utilização dessa ferramenta se originou nas aulas da disciplina optativa Análise da paisagem utilizando Open Data Kit (ODK) e KoBoToolbox, no Programa de Pós-Graduação em Geografia. Para o desenvolvimento das atividades, o questionário foi estruturado no escritório e em campo utilizando-se o KoBoToolbox pelo aparelho de celular, o que possibilitou o deslocamento para os estabelecimentos de saúde. A cidade de Jataí apresenta nove unidades básicas de saúde e o Hospital das Clínicas que realiza, além dos atendimentos básicos, atendimentos de média e alta complexidade para moradores da cidade e região. O sistema se mostrou uma ferramenta bastante eficaz para o desenvolvimento de atividades em campo.
\end{abstract}

Palavras-chave: Coleta de dados. Metodologias em saúde. Estabelecimentos de saúde.

\begin{abstract}
Public health establishment make up the municipal public health network of cities, and for these develop a quality service that allows access to the population is of fundamental importance know the characteristics of these places. So the objective of this work is to characterize the public health establishments in the city of Jataí - Goiás using the KoBoToolbox system, testing like this the tools it has for health area. The proposal to use this tool took place in the optional discipline Landscape analysis using Open Data Kit (ODK) and KoBoToolbox, in the graduate program in Geography. For the development of activities, the questionnaire was structured in the office and in the field we use the KoBoToolbox by mobile phone, allowing the displacement for healthcare facilities. In the Jataí city has nine basic health units and the Clinical Hospital that performs besides the basic services, medium and high complexity services for city and region residents. The System proved to be a very effective tool for the development of field activities.
\end{abstract}

Keywords: Data Collection. Health Methodologies. Health establishment.

Recebido em: 14/01/2022

Aceito para publicação em: 27/01/2022.

\begin{tabular}{llllll}
\hline Hygeia & Uberlândia - MG & Edição especial: X GeoSaude & Fev./2022 & p. 120-135 & Página 120
\end{tabular}




\section{INTRODUÇÃO}

A saúde no Brasil, desde a criação do Sistema Único de Saúde (SUS) em 1990, vem passando por um processo de estruturação que visa à melhoria dos atendimentos aos seus usuários. A lei de criação do SUS prevê atendimento de qualidade com equidade. Com o intuito de buscar a integralização e a universalização dos serviços de saúde, a partir da Portaria Gabinete Ministerial/Ministério da Saúde GM/MS no 4.279/2010, de acordo com o disposto na Constituição, foi proposta a regionalização da atenção à saúde, estabelecendo diretrizes para a organização da rede no âmbito do SUS. Essa portaria seria uma possibilidade de organizar espacialmente os serviços prestados pelo SUS, de forma que sua distribuição favorecesse o acesso por parte da população.

Com isso, as cidades consideradas centros de referência ou cidades-sede devem atender às demandas da população de cidades circunvizinhas dentro de uma determinada região. Essa divisão em região leva em conta, além de fatores geográficos, fatores epidemiológicos e sociais, com vistas a um menor deslocamento dos usuários que estão em busca de atendimento médico.

No Brasil existem 436 regionais de saúde, sendo que 18 delas estão situadas no estado de Goiás (BRASIL, 2019). Hoje, os atendimentos aos usuários destes municípios são gerenciados por servidores por meio dos sistemas de regulação, que de acordo com as listas de espera agendam consultas, exames, cirurgias e internações. Esse sistema de regulação deveria promover celeridade aos atendimentos, mas o que se evidencia são filas imensas que fazem com que os usuários aguardem por anos a realização de determinado procedimento, principalmente cirurgias, chegando em casos extremos de haver a liberação do procedimento post mortem do usuário.

Para evitar esse tipo de situação, as cidades devem priorizar as unidades de saúde como porta de entrada, diminuindo assim os casos de urgência ao aumentarem a prevenção das doenças. Diante disso, é necessário conhecer a realidade de cada local, com vistas a identificar as falhas e a distribuição dos estabelecimentos de saúde. Para auxiliar na identificação desses estabelecimentos existem hoje vários softwares, sistemas e aplicativos. Assim, para a realização deste trabalho e com o intuito de conhecer novas ferramentas que facilitem a pesquisa, principalmente aquelas que envolvem trabalhos de campo, foi utilizado o conjunto de ferramentas KoBoToolbox para construção do questionário com perguntas de caracterização dos estabelecimentos de saúde da cidade de Jataí-GO.

Diante do exposto e com vistas a testar essa nova ferramenta e avaliar sua eficiência para a realização das pesquisas, este trabalho teve por objetivo proceder à caracterização dos estabelecimentos de saúde da rede municipal do município de Jataí-Goiás utilizando o KoBoToolbox.

Com os dados obtidos na pesquisa espera-se fazer um comparativo entre os atendimentos realizados nas unidades básicas de saúde (UBS) e no Hospital das Clínicas (HC) da cidade de Jataí-Goiás, que é sede da Regional Sudoeste II do Estado.

\section{Dinâmica dos serviços de saúde e a geografia}

O entendimento da dinâmica dos serviços de saúde contribui para a melhoria da qualidade de vida da população por meio da identificação dos pontos deficientes de cada área. Para auxiliar nesse reconhecimento tem-se a Geografia da Saúde, que é um ramo da ciência geográfica que busca identificar o acesso aos serviços de saúde e verificar as falhas existentes, contribuindo assim com a gestão do sistema por parte dos órgãos públicos e dos gestores. Associar o espaço em que as pessoas vivem e a saúde se torna de suma importância, pois pode servir como uma ferramenta para a compreensão do espaço social.

Esse contexto de entendimento no qual se insere a Geografia da Saúde surge para analisar os processos de saúde e doença, suas interações com a organização dos equipamentos existentes, considerando, portanto, a unidade espacial, a territorial e a escala (GUIMARÃES, 2015).

Para se entender as realidades nos estudos em saúde é necessário que se faça um diagnóstico da situação para verificar a demanda da população por meio da descrição dos perfis socioeconômico e epidemiológico, do lugar, dos fixos e dos fluxos, das instituições e populações e das políticas públicas que interferem no modo de vida e promovem a segregação social. A partir de todos esses descritores é possível avaliar o processo de saúde-doença.

Nesse viés, Rodrigues (2007) destaca a importância da escala e explica que, no espaço geográfico, a escala geográfica deve ser utilizada nos estudos de saúde devido à necessidade de se considerar as condições de vida da sociedade no espaço, sendo essa condição sinônimo de saúde. A Geografia é

\begin{tabular}{llllll}
\hline Hygeia & Uberlândia - MG & Edição especial: X GeoSaude & Fev./2022 & p. 120-135 Página 121
\end{tabular}


capaz de promover essa articulação entre as diferentes escalas, devido a sua estrutura metodológica e teórica. Guimarães (2015) acrescenta que:

As categorias do espaço (forma, estrutura, e tensão, conexão) e tempo (duração, ciclo, ritmo) são fundamentais para a abordagem geográfica da saúde. Elas ganham concretude em diferentes formas de espaço geográfico (território, lugar, região), que somente podem ser compreendidos no seu tempo (período, processo) (GUIMARÃES, 2015, p. 86).

A região, com sua especificidade, configura-se, conforme Santos (1985, p. 67): "como o resultado das possibilidades ligadas a uma certa presença, nela, de capitais fixos exercendo determinado papel ou determinadas funções técnicas e das condições de seu funcionamento econômico" fornecidas por uma série de relações, redes políticas, econômicas e geográficas. "Os fixos não são apenas formas", eles são dotados de conteúdo fornecido, principalmente, pelos atores, firmas, instituições nacionais ou multinacionais que configuram suas lógicas, suas necessidades produtivas, suas organizações internas.

Esses capitais fixos podem ocupar a mesma região no espaço, o que não necessariamente significa uma convivência "harmoniosa" entre eles, a não ser quando fazem parte de uma mesma associação, de um mesmo conglomerado (SANTOS, 1985, p. 68). Brito (2005) afirma que as "instituições e firmas devem ser consideradas não apenas por sua lógica interna de produção, mas também pela sua capacidade de gerar a circulação de mercadorias".

Nesse contexto, Santos (1985, p. 72) considera que a "articulação entre diversas frações do território se opera exatamente através dos fluxos que são criados em função das atividades, da população e da herança espacial". Nesse sentido, identificando os fixos da área da saúde que fazem parte da cidade de Jataí, espera-se alcançar os objetivos traçados. É importante, além dos fixos, realizar a identificação dos atores que fazem parte da área da saúde e sua atuação para melhoria da saúde da população.

\section{Importância da cidade de Jataí na rede de saúde}

$\mathrm{Na}$ área da saúde, o Sudoeste Goiano conta com duas regionais que atendem aos municípios ao seu redor. A Regional de Saúde Sudoeste I, com sede em Rio Verde, conta com 18 municípios, entre eles, além da cidade sede, Acreúna, Santa Helena e São Simão.

A cidade de Jataí integra a Regional de Saúde Sudoeste II, da qual também fazem parte os municípios de Aporé, Caiapônia, Chapadão do Céu, Doverlândia, Mineiros, Perolândia, Portelândia, Serranópolis e Santa Rita do Araguaia. Jataí é responsável por oferecer serviços de média e alta complexidade a seus moradores e dos municípios pertencentes à Regional. Os atendimentos a pessoas de municípios vizinhos são realizados graças a pactos e convênios, que geralmente preveem uma contrapartida da cidade de origem, com vistas a auxiliar nos custos dos tratamentos, atendimentos, entre outros.

Comparando esses dois municípios, Jataí é considerado um centro de saúde importante, porém, o município de Rio Verde oferece, através da iniciativa privada, uma rede de saúde mais ampla. Mesmo assim, Jataí possui uma boa influência sobre os demais municípios em relação ao atendimento da saúde. $\mathrm{Na}$ cidade, os usuários encontram uma rede de saúde composta por serviços particulares e públicos, em Rio Verde a grande maioria é composta por serviços e profissionais da rede particular de saúde.

Além dos moradores da cidade de Jataí, diariamente, a rede pública de saúde recebe várias pessoas para realizarem tratamentos ou atendimentos. A análise dos atendimentos prestados e dos custos demandados auxilia no planejamento das ações a serem desenvolvidas.

Santos (2008) destaca a função dos centros de serviços que determinadas cidades desempenham em relação a outras regiões. Nesse sentido, alguns desses serviços tornam-se restritos pelos seus custos e pelas dificuldades das comunicações. Souza (2003) explica que devemos abordar as redes urbanas em uma perspectiva que considera uma relação de dependência, seja ela de consumo ou de produção, com outras cidades, apresentando, assim, o termo área de influência.

As unidades de saúde, para melhor atenderem à população, devem estar distribuídas de forma a facilitar 0 acesso. Porém, alguns autores possuem diferentes concepções sobre os fatores que influenciam na escolha da população por determinada unidade, sendo eles: geográficos, afinidade, qualidade no atendimento e oferta dos serviços de interesse. "Nesse contexto, é pertinente compreender os fatores que influenciam a utilização dos serviços de saúde identificando razões para

Hygeia Uberlândia - MG $\quad$ Edição especial: X GeoSaude $\quad$ Fev./2022 $\quad$ p. 120-135 Página 122


possíveis diferenças na procura, na satisfação com o cuidado recebido e nos resultados alcançados" (VIEGAS; CARMO; LUZ, 2015, p 102).

Outro fator que influencia essa escolha é o tempo de espera por determinadas consultas ou exames. Devido à demora em alguns casos, os usuários optam por se deslocarem para locais mais distantes, porém vão realizar o atendimento de forma mais completa, com isso, vão aos hospitais de referência.

\section{Aplicação do KoBoToolbox para realização de pesquisas}

No meio acadêmico e profissional é comum e importante o desenvolvimento de pesquisas com a realização de trabalhos de campo. O trabalho de campo permite uma maior percepção por parte do pesquisador acerca do objeto a ser estudado e a inserção de detalhes não perceptíveis apenas em buscas em bancos de dados. É comum também a utilização de instrumentos de coleta de informações em campo, seja para realização de entrevistas ou para observar as características do meio investigado. Após essa coleta, o estudo avança para a estruturação do banco de dados e a posterior análise das informações. Essas etapas demandam tempo dos pesquisadores, alguns deles, devido à falta de disponibilidade para realização dessa ação, optam por terceirizar a construção do banco de dados.

Com o advento das novas tecnologias, algumas delas vieram para auxiliar as atividades do dia a dia, permitindo uma maior eficácia no desenvolvimento das tarefas. Um conjunto de ferramentas que veio para integrar o rol de possibilidades é o KoBoToolbox. De acordo com Silva (2019), o KoBoToolbox é um software que permite a coleta de dados, a análise e o gerenciamento com vistas a subsidiar a tomada de decisões nas mais diversas áreas, permitindo a estruturação de gráficos, tabelas, relatórios e mapas e ainda a exportação dos dados para serem utilizados em outros sistemas.

O autor Mota Junior (2017) elenca como uma das principais vantagens do KoBoToolbox a otimização do tempo gasto durante a realização das pesquisas de campo:

A otimização no processo de coleta de dados mostra-se como uma das maiores vantagens na utilização do software, que além de poupar de questionários de papel que necessitam de uma logística e espaço físico amplos, que acarreta uma demando por local, material e pessoal, a plataforma também auxilia diminuindo os possíveis erros durante a transição das informações que estão nos questionários para as planilhas, por ocorrer de forma automática, sendo meramente necessário a reconectar a uma rede wi-fi. (MOTA JUNIOR, 2017. p 16).

Este sistema permite a criação de questionários que podem ser aplicados off-line e, após a inserção dos dados, esses são transferidos para o servidor no momento em que houver rede de internet disponível. Automaticamente são criados tabelas, gráficos e mapas, facilitando assim a análise dos dados e dando maior agilidade ao processo de construção do estudo.

\section{MATERIAL E MÉTODOS}

A proposta do trabalho se deu como atividade final da disciplina do Programa de Pós-Graduação em Geografia "Análise da paisagem utilizando Open Data Kit (ODK) e KoBoToolbox". O estudo se baseia em uma análise quali-quantitativa utilizando dados da Secretaria Municipal de Saúde, do Departamento de Informática do Sistema Único de Saúde (DATASUS) e do Cadastro Nacional de Estabelecimentos de Saúde (CNES) para o ano de 2019. Foi realizado também um trabalho de campo, em que foram percorridas todas as unidades de saúde da rede municipal da cidade de Jataí. A partir dos relatórios fornecidos pela secretaria, realizou-se o preenchimento do questionário estruturado no software KoBoToolbox. A figura 1 apresenta a localização e o perímetro urbano da área de estudo com as rodovias (BR 158 e 364) que a interceptam.

\begin{tabular}{llllll}
\hline Hygeia & Uberlândia - MG & Edição especial: X GeoSaude & Fev./2022 & p. 120-135 & Página 123
\end{tabular}


Figura 1 - Jataí (GO): localização da área de estudo, 2020.

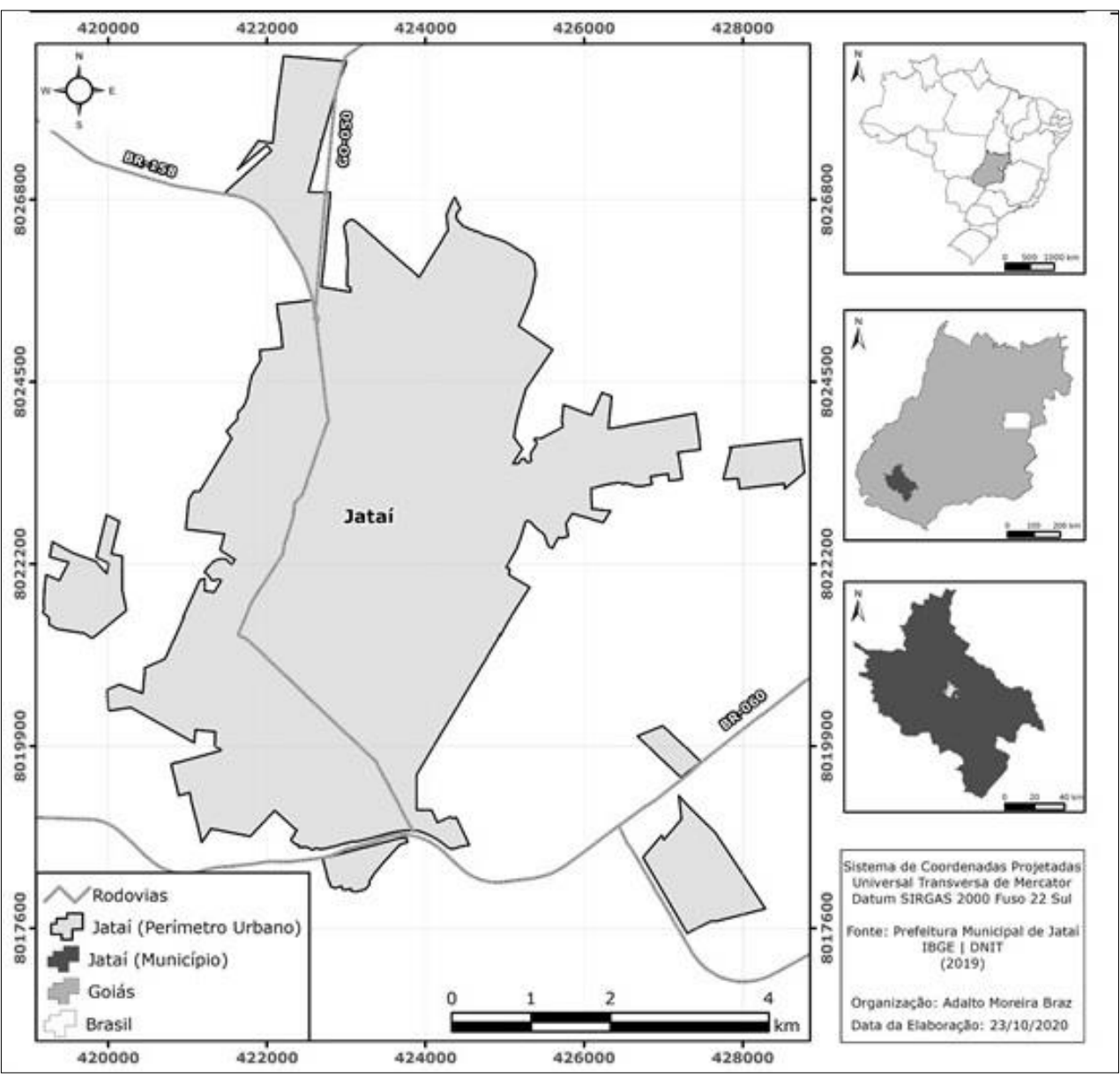

Fonte: os autores, 2020.

A pesquisa foi desenvolvida no município de Jataí-Goiás, no sudoeste Goiano. Jataí é uma cidade do interior do Estado de Goiás, localizada a $320 \mathrm{Km}$ da capital, Goiânia, e a 528,7Km do Distrito Federal. De acordo com o Instituto Brasileiro de Geografia e Estatística - IBGE (2021), a população estimada de Jataí, em 2021, é de 102.065 pessoas, sendo que, conforme o último censo de 2010, a cidade contava com uma população de 88.006 pessoas, das quais 81.010 se encontravam na zona urbana e 6.996 na zona rural, distribuídas em uma área territorial de $7174.220 \mathrm{~km}^{2}$, cuja densidade demográfica era de $12.27 \mathrm{hab} / \mathrm{km}^{2}$.

A rede de saúde municipal possui hoje 14 estabelecimentos de saúde, entre eles, nove Unidades Básicas de Saúde (UBS) na área urbana, três UBS na área rural, nos distritos de Naveslândia, Estância e Assentamento Rio Paraíso, uma Unidade de Pronto Atendimento (UPA) e a Policlínica Municipal. Esses estabelecimentos estão distribuídos em diferentes pontos do município com vistas a facilitar o acesso da população. Para fins da pesquisa foram considerados os estabelecimentos de saúde localizados no perímetro urbano de Jataí.

\section{Sequência das atividades para realização da pesquisa}

Para realizar a pesquisa, foram seguidos os passos: antes de estruturar o questionário no KoBoToolbox, utilizou-se o software Freeplane, um aplicativo livre que permite a elaboração de mapas mentais e organogramas. A figura 2 apresenta o organograma estruturado para a elaboração do questionário. 
Figura 2 - Organograma para estruturação do questionário, 2019.

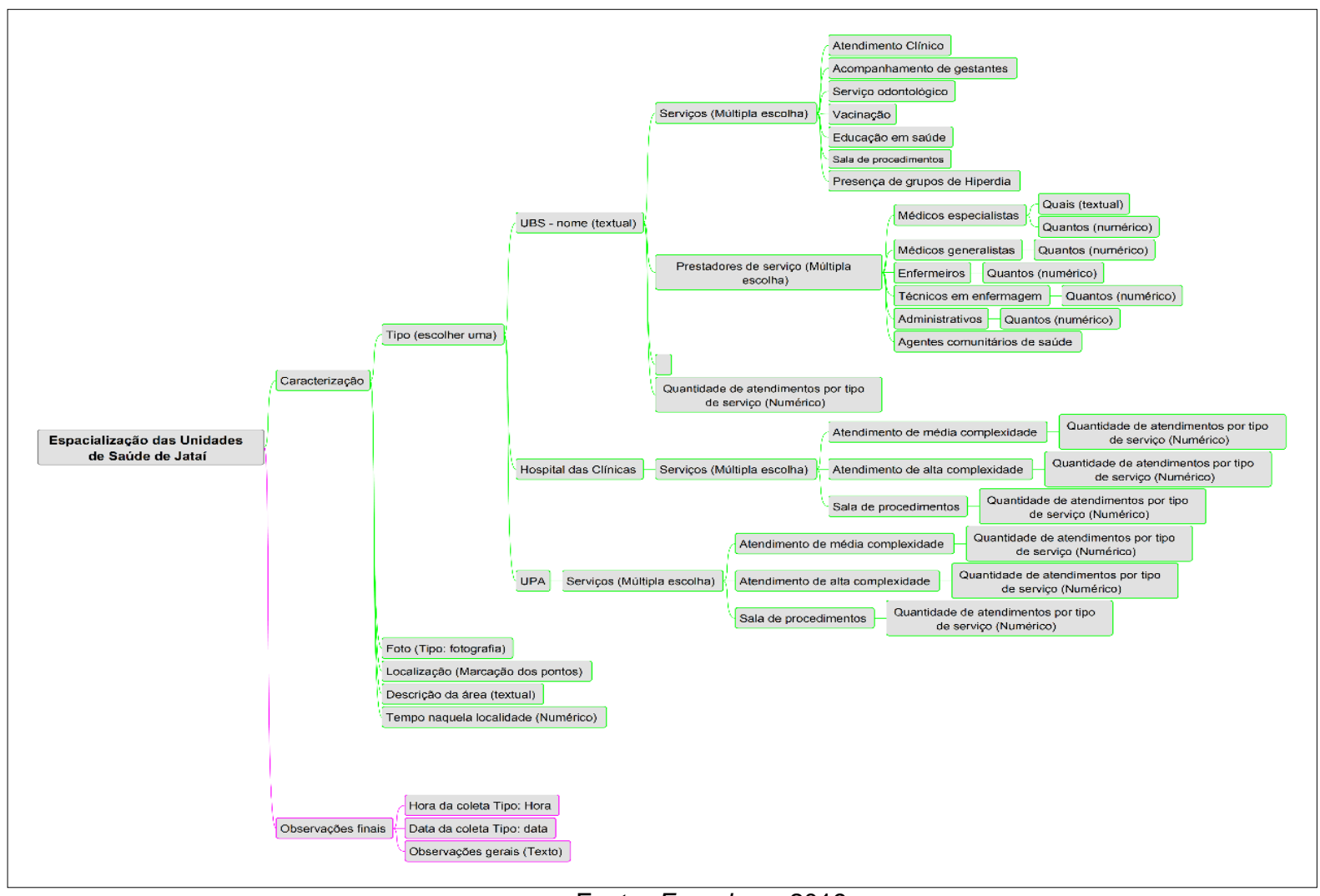

Fonte: Freeplane, 2019

Organização: SILVA, Juliana Freitas, 2019.

Durante a elaboração do questionário, alguns itens foram inseridos e outros suprimidos, isso ocorreu devido à falta de experiência na utilização do aplicativo, o que não permitiu uma visão geral de como seria o trabalho em campo. Nesse sentido, é importante que se desenvolva um piloto para testar se o questionário é aplicável ou se há a necessidade da realização de ajustes. Caso a pesquisa tenha mais de um pesquisador, o software permite o compartilhamento de informações, concedendo permissão somente para visualização ou para visualização e edição, o que é outra vantagem que permite maior agilidade no desenvolvimento do estudo em equipe.

A utilização desse software ocorreu devido à necessidade de esquematização das perguntas que comporiam o questionário no KoBoToolbox. Ele possibilita ao leitor uma visão ampla de quais questões serão importantes para sua pesquisa e a sequência lógica delas.

De posse do organograma, a próxima etapa consistiu na elaboração do questionário no KoBoToolbox. O sistema permite que sejam inseridas questões de múltipla escolha, escolha única, texto, valor número, hora, entre outras. A figura 3 apresenta as opções que o pesquisador tem para elaborar seu questionário. 
Figura 3 - Tipos de perguntas que podem ser elaboradas no KoBoToolbox, 2019.

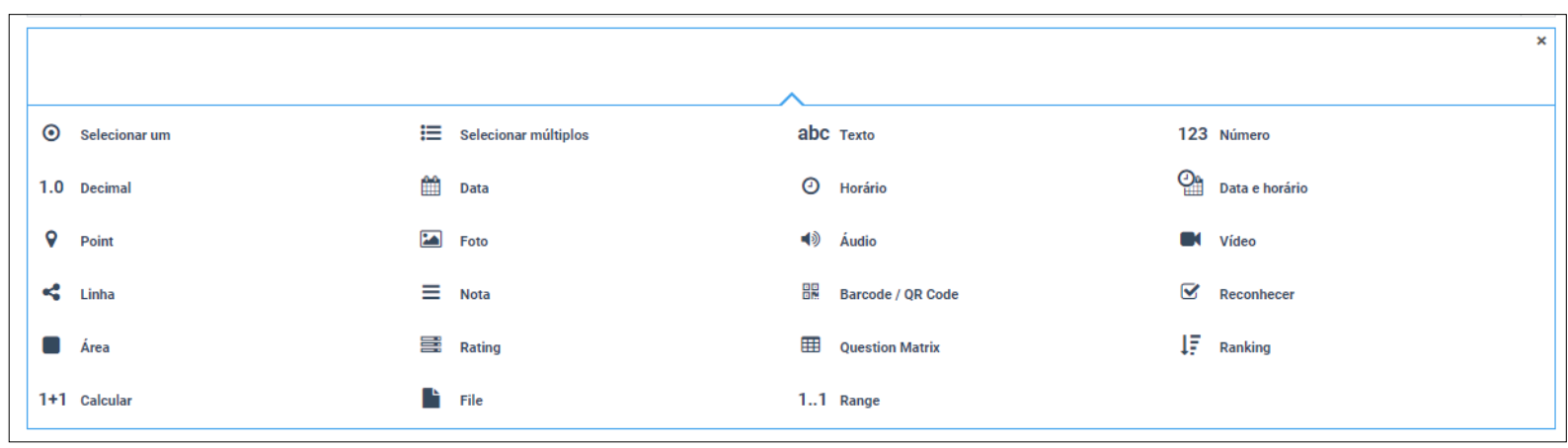

Fonte: KoBoToolbox, 2019.

Organização: SILVA, Juliana Freitas, 2019.

Para que se escolha adequadamente o tipo da pergunta é necessário que haja um organograma bem estruturado, pois nele já consta a previsão da pergunta e a forma da possível resposta pretendida pelo pesquisador. Após a inserção das perguntas e do tipo de resposta para cada uma, o questionário fica com o formato apresentado na figura 4.

Figura 4 - Modelo de questionário elaborado no KoBoToolbox, 2019.

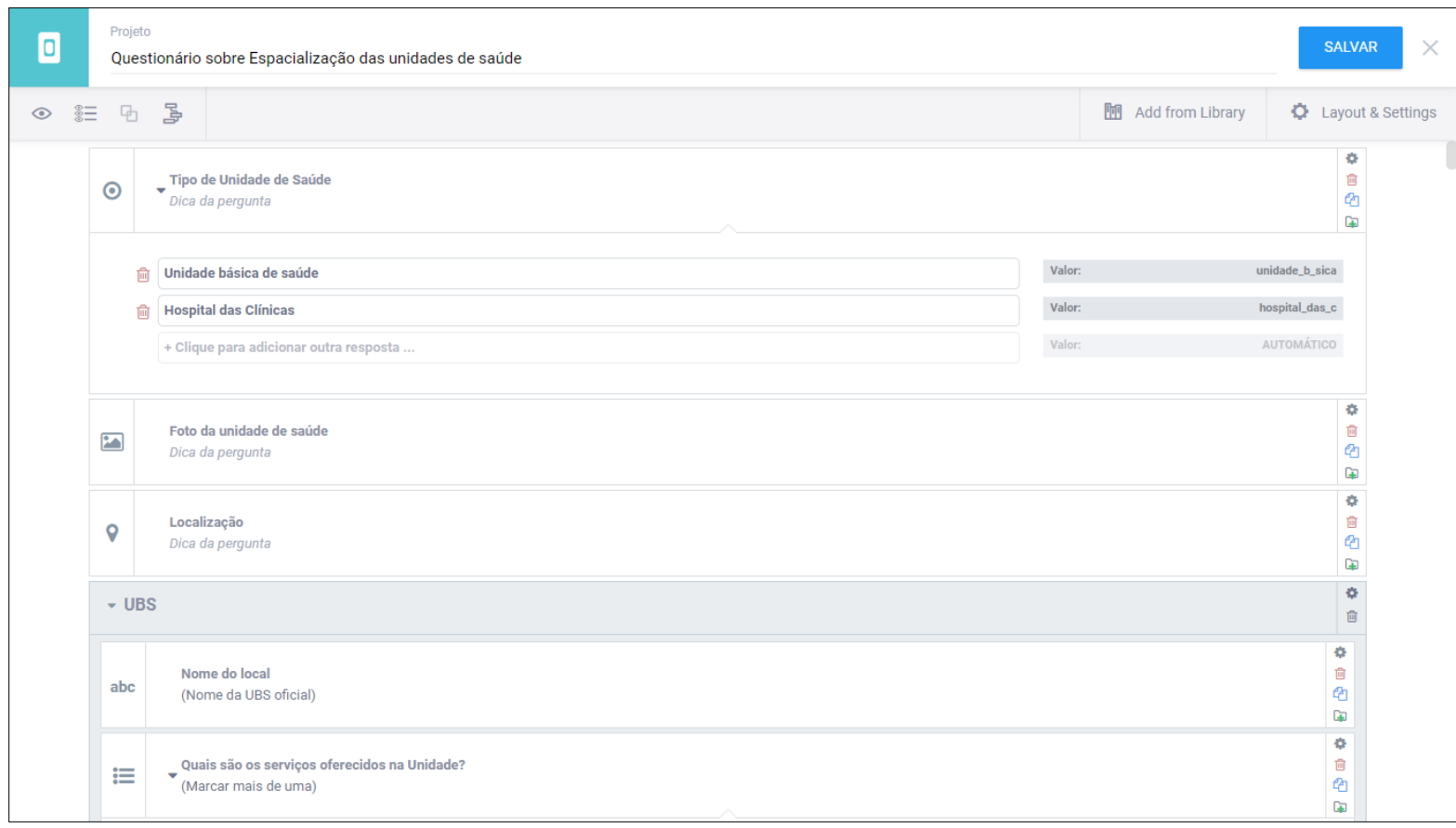

Fonte: KoBoToolbox, 2019

Organização: SILVA, Juliana Freitas, 2019.

A partir da construção das perguntas, o pesquisador pode agrupar as questões referentes a um determinado item como também pode duplicá-las. É possível também duplicar o questionário inteiro.

Com o questionário pronto, foram inseridas as respostas provenientes de relatórios emitidos pela Secretaria Municipal de Saúde. A inserção dessas respostas no questionário se deu para facilitar a estruturação do banco de dados para análise dos resultados. Para tal ação foi utilizado um dispositivo móvel com sistema iOS. Como não existe aplicativo para esse sistema, o questionário foi preenchido utilizando-se 0 navegador web do dispositivo, de forma off-line, através do site https://www.KoBoToolbox.org/. Em dispositivos Android é possível instalar o aplicativo de coleta Kobo Collect.

Hygeia Uberlândia - MG $\quad$ Edição especial: X GeoSaude $\quad$ Fev./2022 $\quad$ p. 120-135 Página 126




\section{RESULTADOS}

Os dados inseridos para preenchimento dos questionários foram disponibilizados pela Secretaria Municipal de Saúde e retirados dos sites DATASUS, Sistema de Informações Hospitalares do SUS (SIHSUS) e CNES.

Após a realização dos trabalhos de campo, foram elaborados mapas, tabelas e gráficos a partir do banco gerado pelo sistema KoBoToolbox. As unidades básicas de saúde da cidade possuem nomes oficiais, porém são popularmente conhecidas pelo nome do bairro em que estão localizadas. No quadro 1, tem-se o nome de cada UBS e como são chamadas.

Quadro 1 - Jataí (GO): nome das unidades básicas de saúde,2019.

\begin{tabular}{|l|l|}
\hline \multicolumn{1}{|c|}{ Nome oficial da UBS } & \multicolumn{1}{c|}{ Nome popularmente conhecida } \\
\hline UBS Aristóteles de Rezende & UBS Vila Brasília \\
\hline UBS Dr. Gilberto Inácio Cardoso & UBS Vila Olavo \\
\hline UBS Dr. José Inácio Cardoso & UBS Vila Sofia \\
\hline UBS Dr. Nestor Cury & UBS Conjunto Rio Claro \\
\hline UBS Dr. Otto Carneiro Maciel & UBS Estrela D'alva \\
\hline UBS James Phillip Minelli & UBS Avenida Goiás \\
\hline UBS José Barros Cruz & UBS Santo Antônio \\
\hline UBS Marcondes Franco Carvalho & UBS Vila Fátima \\
\hline UBS Moisés Maia Firmo & UBS Colméia Park \\
\hline \multicolumn{2}{|c|}{ Fonte: PREFEITURA MUNICIPAL DE JATAÍ, 2019. } \\
Organização: os autores, 2019.
\end{tabular}

Os serviços de saúde podem ser classificados em: públicos ou privados; com ou sem fins lucrativos; atendendo em regime ambulatorial ou de internação. Dentro dessa classificação estão: unidades básicas de saúde; postos de saúde; policlínicas; clínicas de assistência médica; pronto socorro; unidade mista; hospitais (incluindo militares); clínicas odontológicas; clínicas radiológicas; clínicas de reabilitação; laboratórios de análises clínicas; unidades de complementação diagnóstica e/ou terapêutica. Este trabalho coletou informações apenas das unidades básicas de saúde e hospitais da rede pública e situados no perímetro urbano da cidade de Jataí. Na época da pesquisa, ou seja, em dezembro de 2019, o Hospital das Clínica Dr. Serafim de Carvalho estava sob a gestão municipal, porém, no ano de 2020, o referido estabelecimento de saúde passou a ser gerido pelo Estado de Goiás. As figuras de 5 a 16 apresentam os estabelecimentos de saúde da cidade de Jataí. 
Figura 5 - Jataí (GO): UBS Avenida Goiás, 2019.

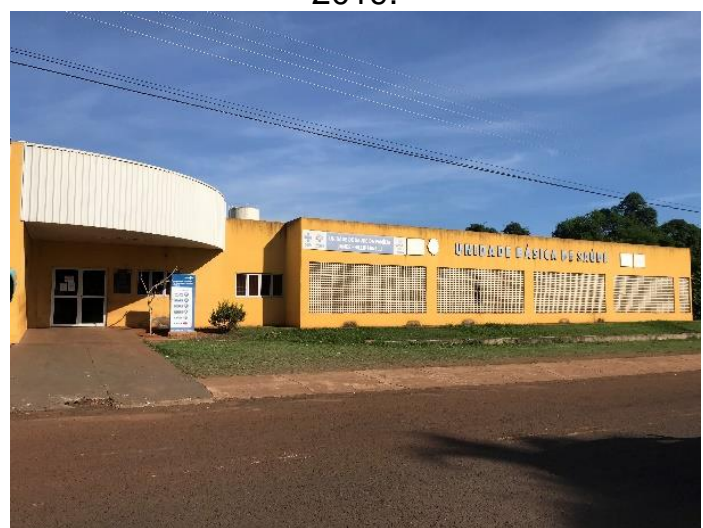

Fonte: SILVA, Juliana Freitas, 2019.

Figura 7 - Jataí (GO): UBS Santo Antônio, 2019.

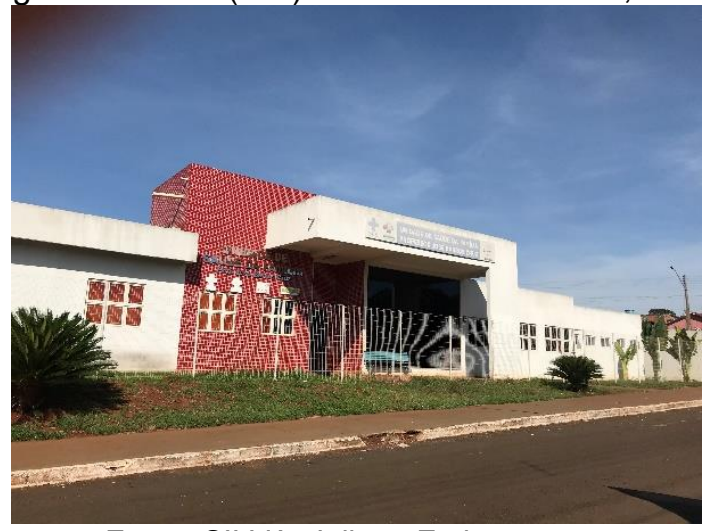

Fonte: SILVA, Juliana Freitas, 2019.

Figura 9 - Jataí (GO): UBS Vila Fátima, 2019.

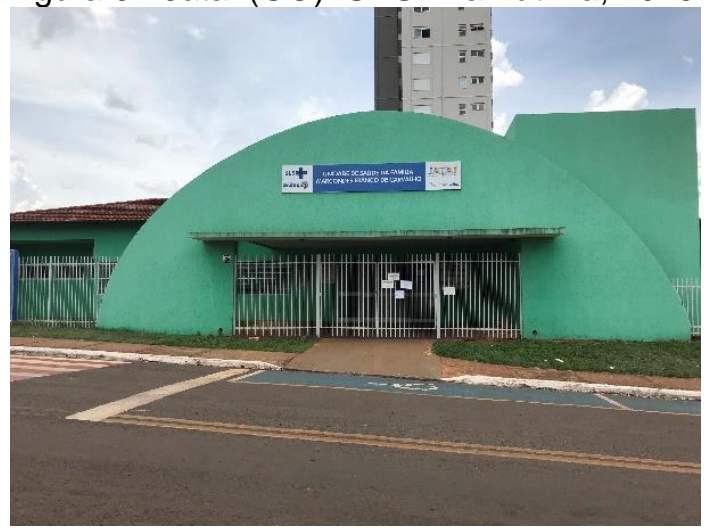

Fonte: SILVA, Juliana Freitas, 2019.
Figura 6 - Jataí (GO): UBS Conjunto Rio Claro, 2019.

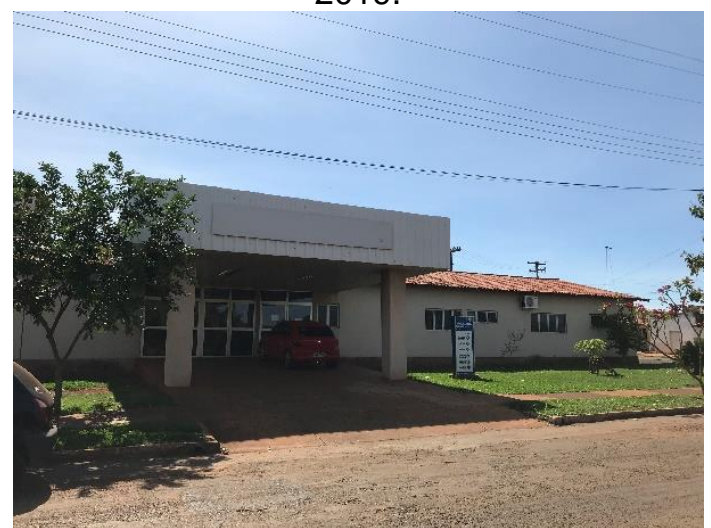

Fonte: SILVA, Juliana Freitas, 2019.

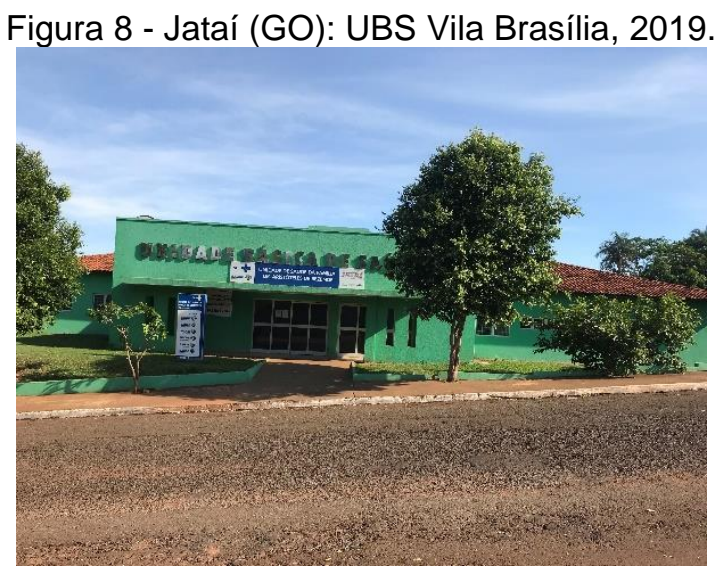

Fonte: SILVA, Juliana Freitas, 2019.

Figura 10 - Jataí (GO): UBS Vila Olavo, 2019.

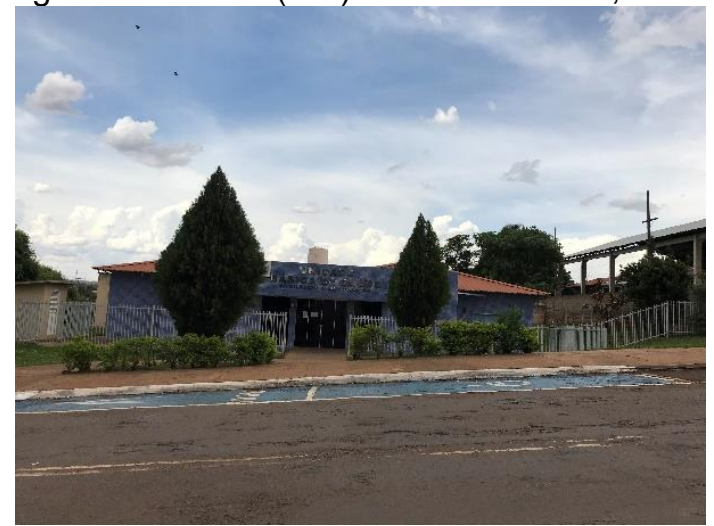

Fonte: SILVA, Juliana Freitas, 2019. 


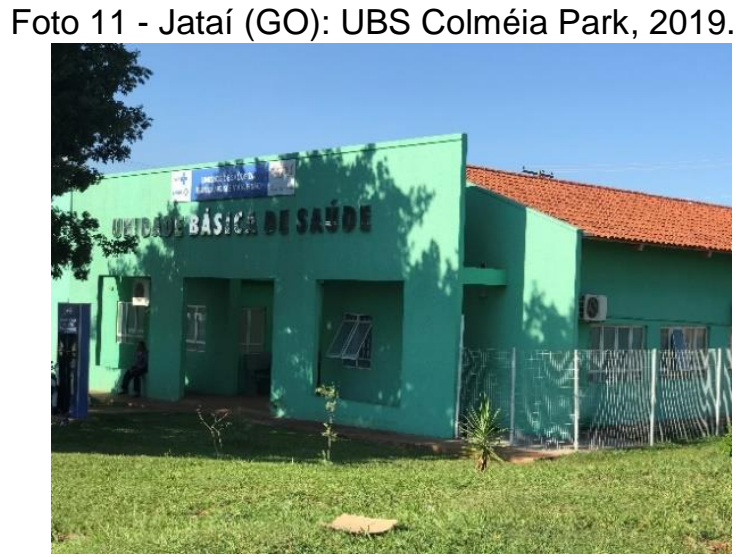

Fonte: SILVA, Juliana Freitas, 2019.

Figura 13 - Jataí (GO): UBS Vila Sofia, 2019.

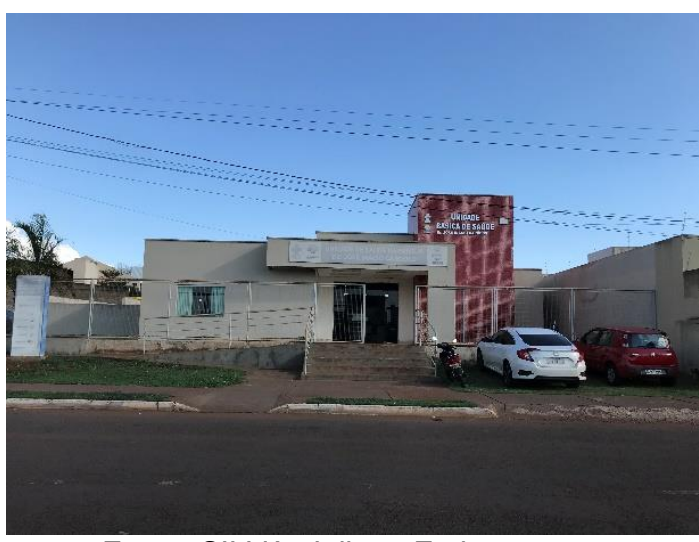

Fonte: SILVA, Juliana Freitas, 2019.

Figura 15 - Jataí (GO): UPA, 2019.

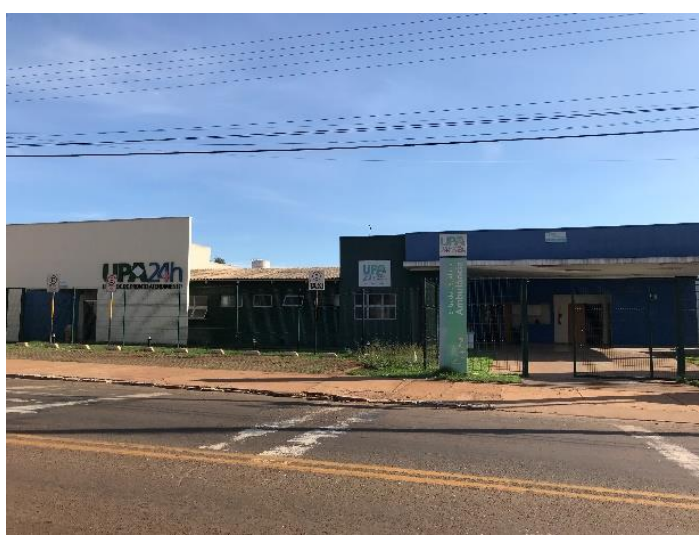

Fonte: SILVA, Juliana Freitas, 2019.
Foto 12 - Jataí (GO): UBS Estrela D'alva, 2019.

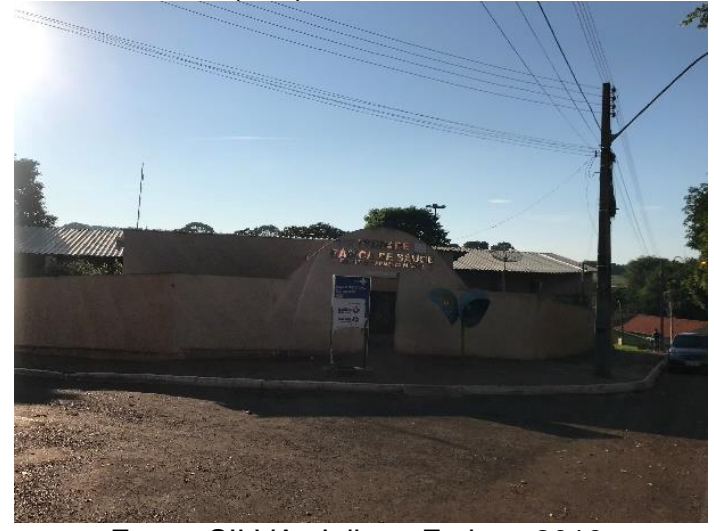

Fonte: SILVA, Juliana Freitas, 2019.

Figura 14 Jataí (GO): Policlínica Municipal, 2019.

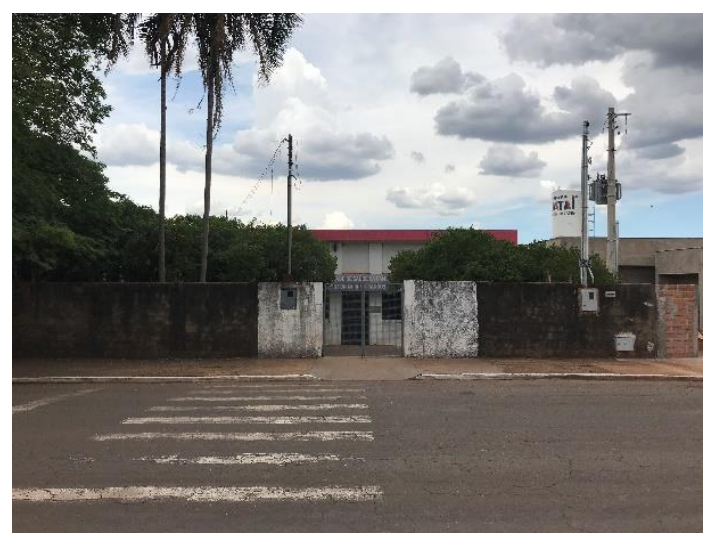

Fonte: SILVA, Juliana Freitas, 2019.

Figura 16 - Jataí (GO): Hospital das Clínicas, 2019.

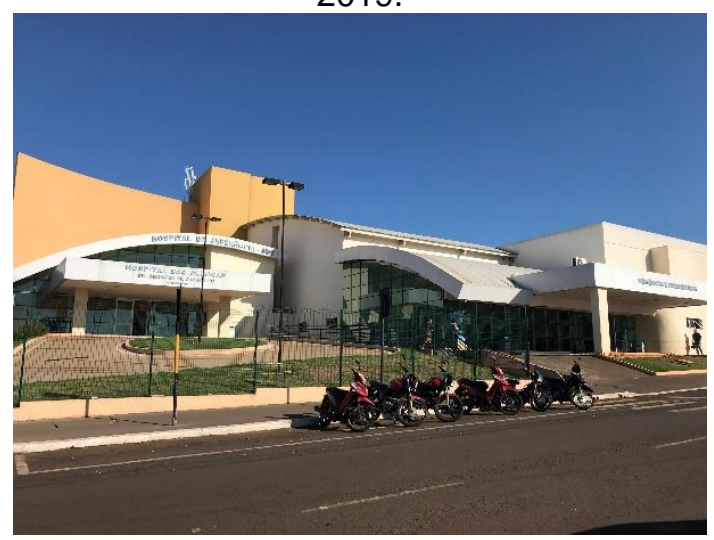

Fonte: SILVA, Juliana Freitas, 2019.

Verificou-se em campo que as unidades de saúde estão bem conservadas, pois a sua grande maioria passou por reforma nos últimos 5 anos. Pelos dados da pesquisa, todas as UBS possuem os mesmos tipos de atendimentos básicos, que são: atendimento clínico, de enfermagem, odontológico, dos agentes comunitários de saúde, de endemias e técnicos em enfermagem. O que diferencia uma unidade da outra é a quantidade de profissionais que realizam o atendimento em cada local. Os dados analisados se referem aos atendimentos realizados nas unidades nos meses de agosto e setembro de 2019.

Hygeia Uberlândia - MG $\quad$ Edição especial: X GeoSaude $\quad$ Fev./2022 $\quad$ p. 120-135 Página 129 
Em relação aos médicos provenientes do programa mais médicos, das nove unidades, cinco possuem profissionais de Cuba, quatro são clínicos médicos e um possui especialização em Saúde da Família.

Para atendimentos nas unidades, as consultas se dão por agendamento e acolhimento. Cada profissional determina a quantidade de atendimentos conforme a demanda de sua área de abrangência nos agendamentos. O acolhimento é disponibilizado ao usuário como forma de avaliar a sua necessidade de atendimento imediato ou agendado utilizando a classificação de risco.

Quanto ao tempo de espera desses usuários pela realização da consulta, as respostas variam entre 5 a 40 dias, dependendo do tipo de atendimento necessário. Para realização dos exames o usuário entrega o pedido na recepção da unidade e os atendentes lançam o pedido no Sistema Nacional de Regulação (SISREG) e, após liberação para realização dos exames, o usuário é informado, retira a liberação para comparecer em data e local marcado para coleta de material.

Em relação ao atendimento de pacientes de outras cidades, seis unidades informaram que atendem pacientes residentes de outras localidades, duas não recebem e uma não informou. As cidades atendidas dependem da localização das unidades, mas em sua maioria são de cidades vizinhas como: Rio Verde, Serranópolis, Mineiros, Perolândia. Apenas uma unidade relatou que recebe pacientes de locais mais distantes, até mesmo de outros países, como Venezuela e Cuba.

A figura 17 apresenta a quantidade de atendimentos realizados pelas equipes de enfermagem e médica de cada unidade.

Figura 17 - Jataí (GO): quantidade de atendimentos nas UBS, 2019.

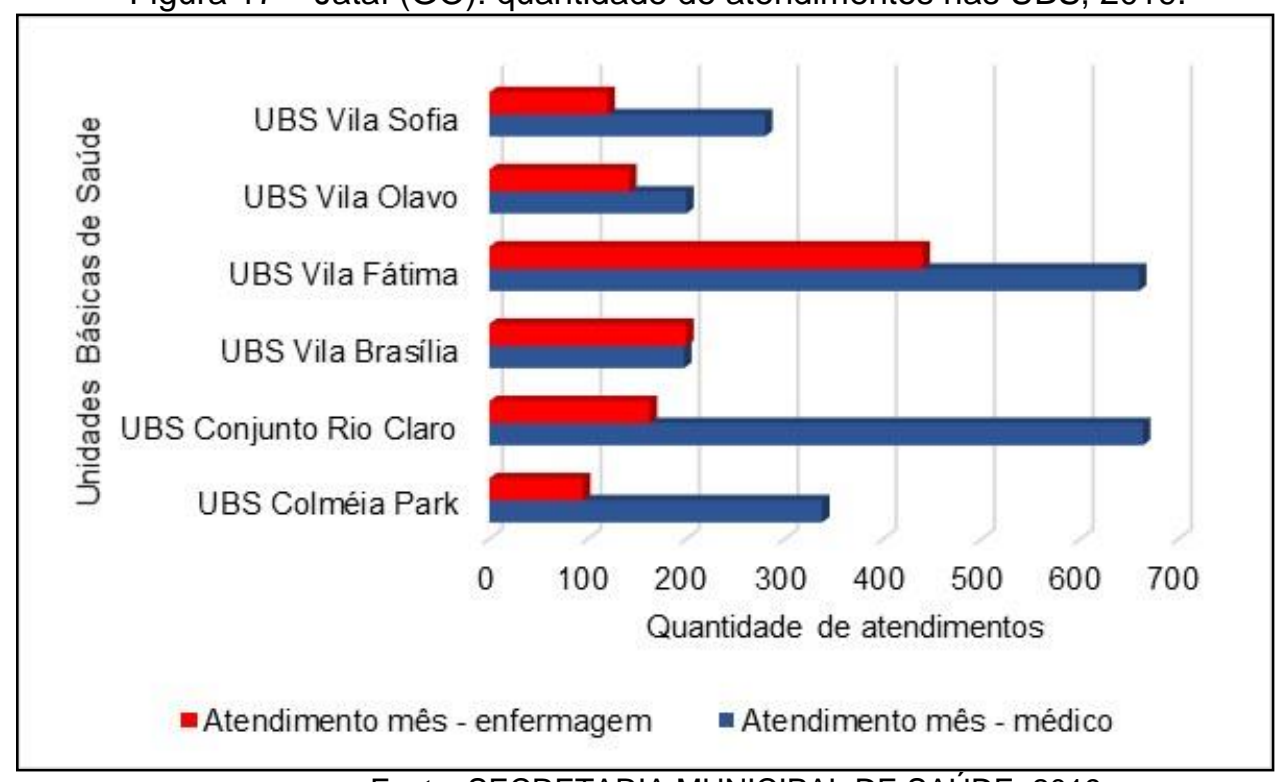

Fonte: SECRETARIA MUNICIPAL DE SAÚDE, 2019

Organização: os autores, 2019.

As unidades Avenida Goiás, Estrela D'alva e Santo Antônio não informaram a quantidade de atendimentos realizados.

Pela distribuição no mapa se percebe que as unidades abrangem uma boa parte da população, facilitando assim o deslocamento para os estabelecimentos de saúde. Porém o deslocamento para o Hospital das Clínicas se torna mais difícil, principalmente para moradores dos bairros Estrela D'alva, Francisco Antônio e Residencial Morada do Sol, que são mais afastados da parte central da cidade.

A figura 18 apresenta a localização de cada uma por meio do mapa gerado pelo KoBoToolbox, segundo o tipo de unidade de saúde. 
Figura 18 - Jataí (GO): estabelecimentos de saúde, por tipo, 2019.

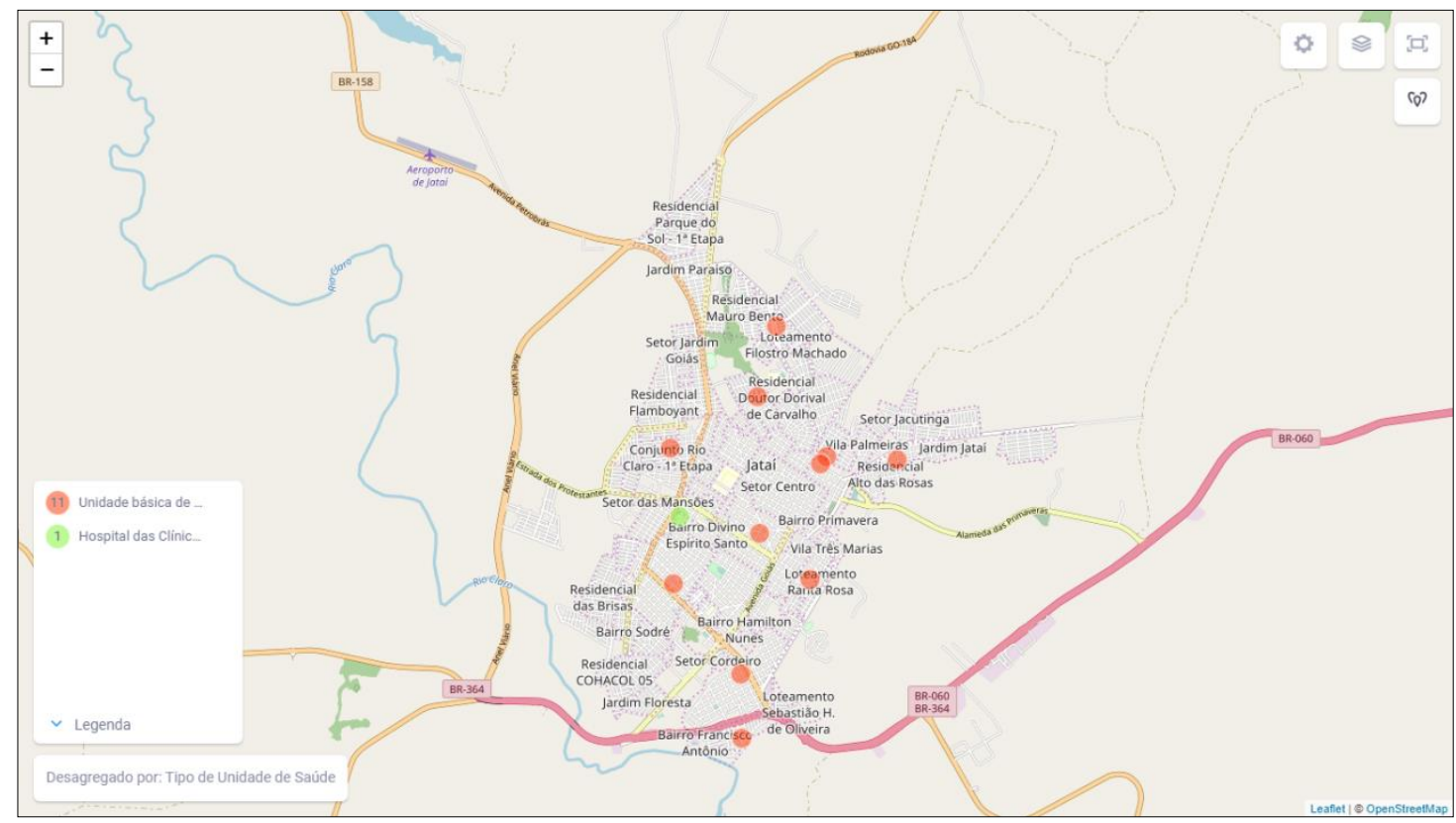

Fonte: KoBoToolbox, 2019

Organização: os autores, 2019.

A figura 18, que é denominada sistema de mapa, é simples, mas permite que o pesquisador crie figuras de acordo com um tipo de pergunta que foi inserida. A figura 18 foi desagregada por tipo de unidade de saúde, contudo, ao se escolher outra categoria, o sistema altera a sua apresentação. Na figura 19 foi selecionado o descritor "nome do local" para demonstração de outras formas de exposição.

Figura 19 - Jataí (GO): estabelecimentos de saúde, por nome do local, 2019.

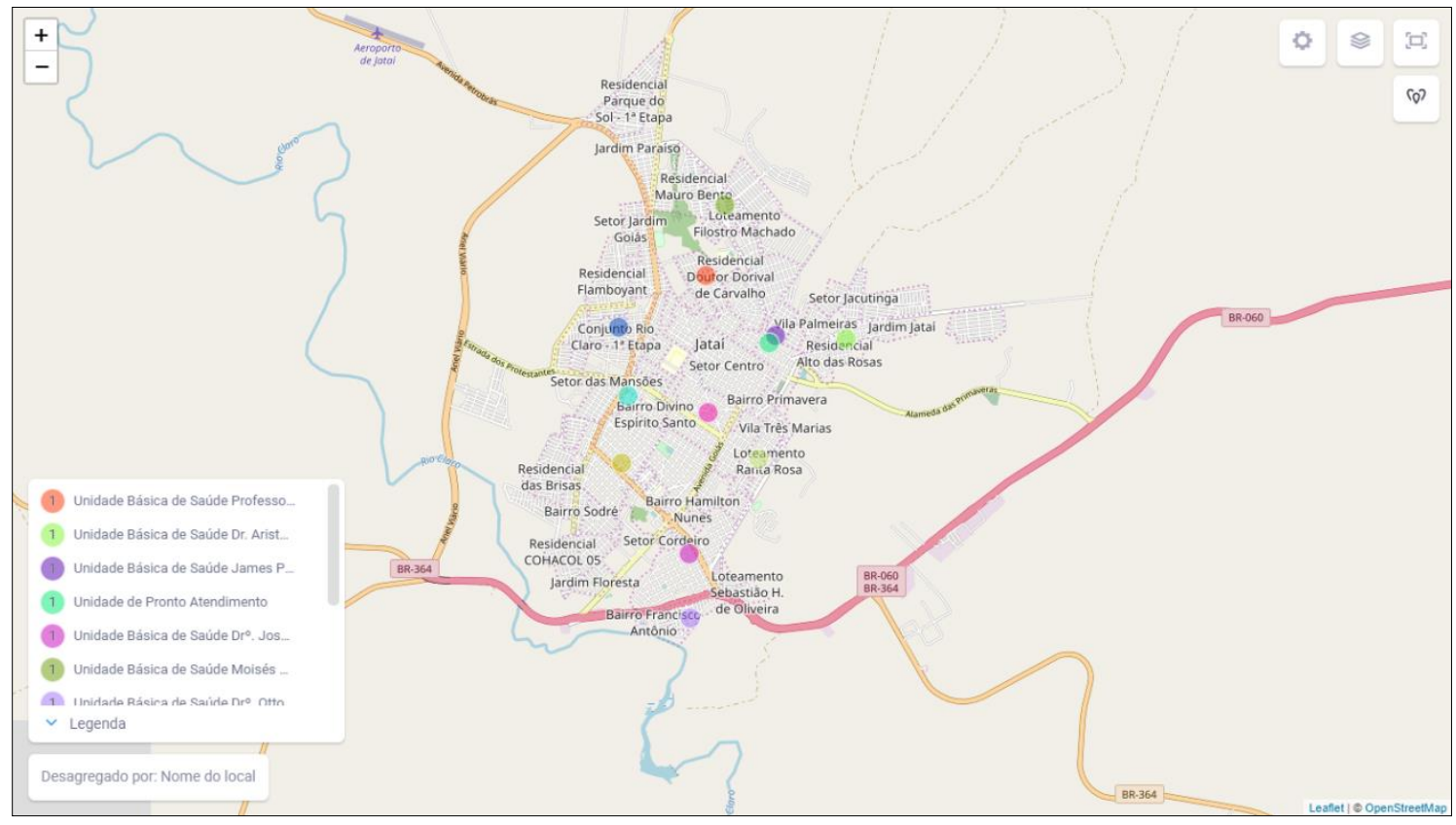

Fonte: KoBoToolbox, 2019.

Organização: os autores, 2019. 
Dependendo do tipo do trabalho a ser realizado essa ferramenta de criação de mapas já confere mais celeridade à conclusão da pesquisa, reduzindo também os custos de execução. Mas caso o pesquisador queira fazer um mapa mais elaborado utilizado outros softwares é possível fazer o download das coordenadas coletadas em campo.

O ponto verde da figura 18 marca o local do Hospital das Clínicas, que é um hospital geral que contém atividades ambulatoriais, atenção básica e de média complexidade e hospitalar de média e alta complexidade. O fluxo dos usuários é através de demanda espontânea e referenciada. De acordo com - CNES (2019), tem como atividade principal a assistência à saúde e a assistência a emergências. De acordo com esse mesmo banco de dados, conta com 543 profissionais cadastrados, entre pessoal administrativo, clínico e demais especialidades. Na figura 20 tem-se a quantidade de atendimentos realizados no mês de junho de 2019 por especialidade médica.

Figura 20 - Jataí (GO): quantidade de profissionais e atendimentos no Hospital das Clínicas, 2019.

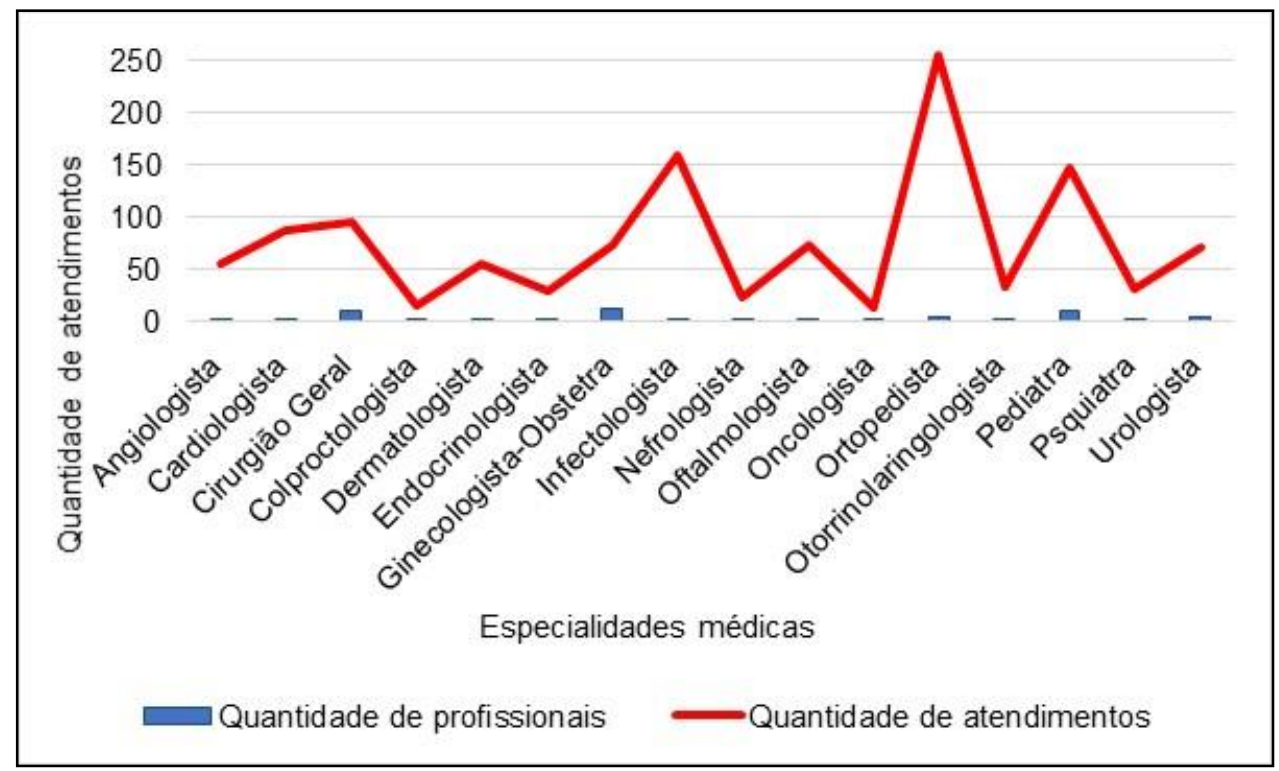

Fonte: SECRETARIA MUNICIPAL DE SAÚDE, 2019.

Organização: os autores, 2019.

Esses dados se referem aos atendimentos realizados nos ambulatórios, que são consultas agendadas pelo sistema SISREG; por meio desse sistema são agendadas consultas e realizados exames médicos. O tempo de espera dos pacientes para realização de consultas e de exames se mostrou variável de acordo com a pesquisa realizada, demorando de 10 a 30 dias, conforme as informações prestadas.

Segundo Ramires (2013), os hospitais universitários, ao prestarem serviços de alta complexidade em cidades médias, produzem fortes fluxos na região e em escala extra regional. Afirma ainda que "os serviços de alta complexidade se concentram principalmente em cidades de grande e médio porte, produzindo fluxos de pessoas, produtos e informações que reforçam o papel polarizador das atividades econômicas dessas localidades" (RAMIRES, 2013, p. 202). O HC de Jataí ainda não é um hospital universitário, mas já está com tramitação para tal alteração, isso fará com que mais serviços sejam prestados à comunidade.

O hospital recebe pacientes de cidades vizinhas para atendimento, sendo que os agendamentos só ocorrem para os ambulatórios, pois o setor de urgência e emergência é porta aberta, atendendo por livre demanda. Somente quando os pacientes precisam ser deslocados para Goiânia, Santa Helena ou outra cidade é necessário que recebam autorização para entrada no outro estabelecimento de saúde.

No software KoBoToolbox a quantidade de atendimentos aparece de forma individual, assim, para confecção do gráfico, utilizou-se as informações presentes no banco de dados gerado. A figura 21 apresenta a forma como o relatório do software apresenta os resultados de atendimento.

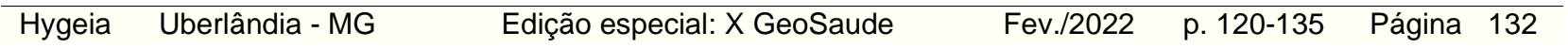


Figura 21 - Como os dados de quantidade de atendimentos são apresentados no KoBoToolbox.

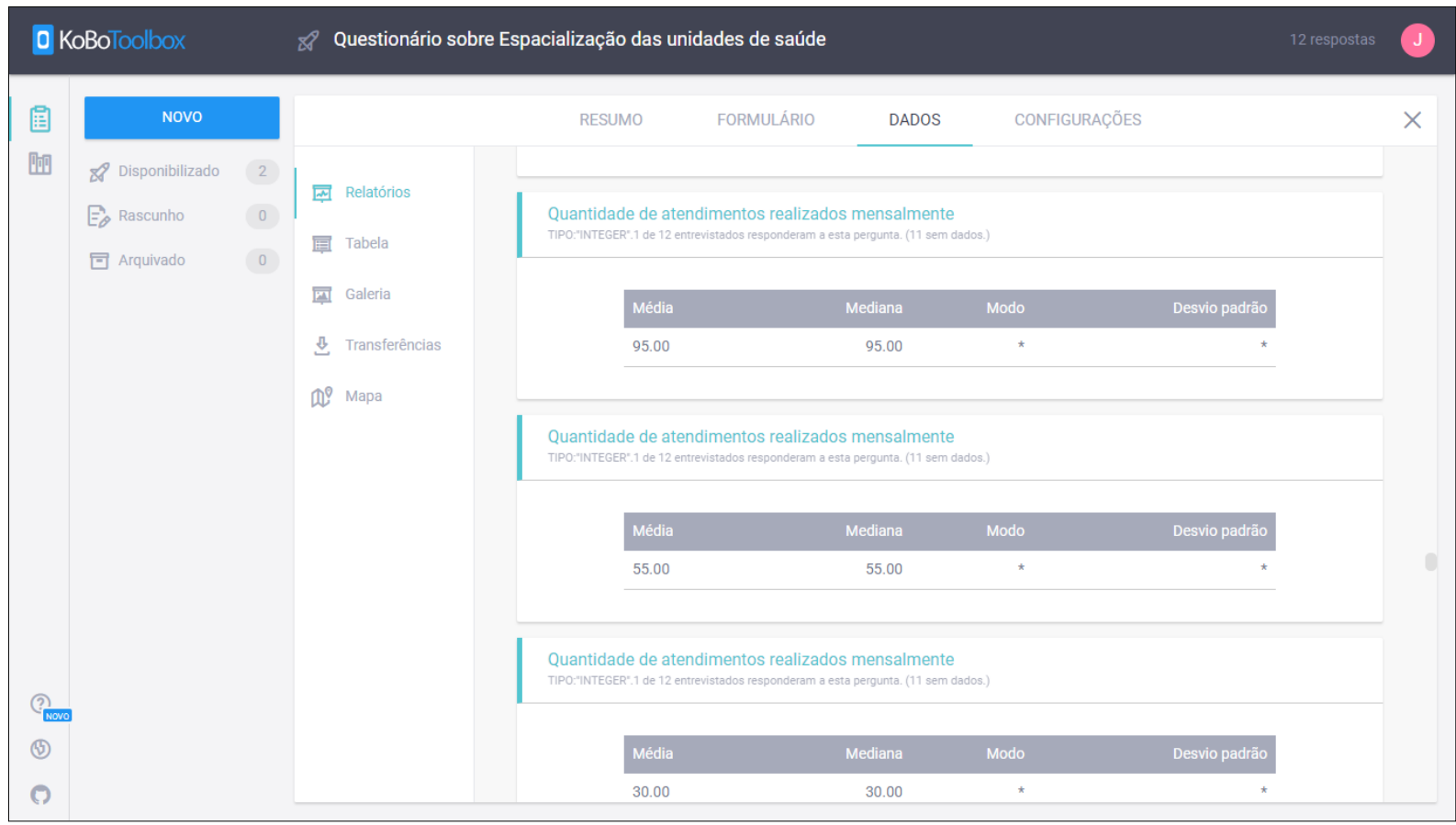

Fonte: KoBoToolbox, 2019

Organização: os autores, 2019.

O banco de dados é disponibilizado em formatos XLS, CSV, Anexos de mídia (ZIP), Coordenadas GPS (KML), analisador Excel e Etiquetas SPSS.

Na coleta dos dados, foi marcado o ponto da Policlínica Municipal de Jataí, que pode ser vista na foto 10. A Policlínica atende pacientes agendados para atendimentos especializados para tratamento de hanseníase, tuberculose, saúde da mulher entre outros. Para esses atendimentos os pacientes devem ser encaminhados pelas UBS. São realizadas campanhas que também identificam os usuários que necessitam dos atendimentos prestados por ela e com isso recebem encaminhamento para atendimento e tratamento. Neste local há ainda a farmácia que faz a entrega de medicamentos para usuários com receitas médicas, a maioria são remédios para tratamento de doenças crônicas.

$\mathrm{Na}$ figura 15 tem-se a Unidade de Pronto Atendimento que permaneceu fechada no período de junho de 2019 a agosto de 2020. A unidade havia sido fechada por conta da falta de recursos municipais para a sua manutenção, porém no ano de 2020 , por conta da pandemia do novo coronavírus (SARSCOV19), foi reaberta e também começou a receber pacientes com COVID-19, o que foi um ganho para a população, pois os atendimentos estavam concentrados no Hospital das Clínicas.

Em relação à utilização do KoBoToolbox, observa-se que a ferramenta se mostrou eficiente e facilitou tanto a transferência dos dados que estavam em relatórios impressos, quanto a tabulação dos mesmos. Durante um estudo realizado em 2020, os autores Da Silva e Silva (2020) fizeram a comparação entre a aplicação de questionários usando o KoBoToolbox e questionários impressos, ao término da pesquisa verificaram que houve a redução de 45 minutos para realização do campo, ou seja, uma diminuição de $75 \%$ do tempo gasto quando usaram o software. Essa otimização da análise permite ao pesquisador despender mais tempo na leitura e ampliar as discussões durante a estruturação dos seus trabalhos.

\section{CONSIDERAÇÕES FINAIS}

Após o término dos trabalhos de campo e das análises, percebeu-se que o KoBoToolbox é uma ferramenta que veio para auxiliar os pesquisadores no decorrer das suas atividades. Ele facilita a coleta dos dados, a estruturação do banco e a análise dos mesmos. É uma ferramenta flexível, gratuita e de fácil manuseio, sendo que o pesquisador ainda tem a opção de trabalhar utilizando o aparelho móvel ou o computador. Dependendo da atividade uma forma ou outra se torna mais adequada para o desenvolvimento da pesquisa.

\begin{tabular}{llllll}
\hline Hygeia Uberlândia - MG & Edição especial: X GeoSaude & Fev./2022 & p. 120-135 Página 133
\end{tabular}


No que tange ao tema analisado, considera-se que as unidades de saúde possuem um pequeno contingente de servidores, o que dificulta o acesso da população aos serviços de saúde, fazendo com que haja filas de espera para os atendimentos solicitados.

Geograficamente as unidades de saúde estão localizadas em pontos estratégicos da cidade, porém existe a demanda por mais estabelecimentos devido à abertura de novos bairros com grande contingente populacional.

\section{REFERÊNCIAS}

BRASIL. Portaria no 4.279, de 30 de dezembro de 2010. Estabelece diretrizes para a organização da Rede de Atenção à Saúde no âmbito do Sistema Único de Saúde (SUS). Disponível em: http://bvsms.saude.gov.br/bvs/saudelegis/gm/2010/prt4279 3012 2010.html. Acesso em: 03 jul 2019.

BRASIL. Ministério da Saúde. Departamento de Informática do SUS (DATASUS), 2019. Disponível em: http://www2.datasus.gov.br/DATASUS/index.php. Acesso em: 07 out. 2019.

BRITO, T.M.A. Reflexões sobre a região. Anais do X Encontro de Geógrafos da América Latina 20 a 26 de março de 2005 - Universidade de São Paulo.

CADASTRO NACIONAL DOS ESTABELECIMENTOS DE SAÚDE. Disponível em: http://www.cnes.datasus.gov.br. Acesso em: 04/11/2019.

DA SILVA, S. S.; SILVA, M. R. Utilização do KoBoToolbox como ferramenta de otimização da coleta e tabulação de dados em pesquisas científicas. Geoambiente On-line, [S. I.], n. 36, p. 122-140, 2020. DOI: $10.5216 /$ revgeoamb.vi36.58264. Disponível em:

https://www.revistas.ufg.br/geoambiente/article/view/58264. Acesso em: 13 jan. 2022. https://doi.org/10.5216/revgeoamb.vi36.58264

Freeplane. Disponível em:<https://freeplane.br.uptodown.com/windows >. Acesso em: 12 jul. 2019.

GUIMARÃES, Raul Borges. Saúde: fundamentos de Geografia humana. São Paulo: Editora Unesp Digital, 2015.

IBGE - Instituto Brasileiro de Geografia e estatística. Cidades. Disponível em <http://cidades.ibge.gov.br/xtras/home.php>. Acesso em: 05 mai 2021.

KoBoToolbox. Disponível em: <https://www.KoBoToolbox.org/>. Acesso em: 12 jul. 2019.

MOTA JUNIOR. C. R.; CUNHA, J. M. As tecnologias de informação e comunicação (TIC) como ferramenta em pesquisas acadêmicas: análise do software KoBoToolbox. Revista Brasileira de Iniciação Científica, Itapetininga, n. 9, p. 13-21, 2017.

PREFEITURA MUNICIPAL DE JATAÍ. Unidades Básicas de Saúde - 2019. Disponível em: <https://www.jatai.go.gov.br/secretaria-da-saude/unidades-de-saude-ambulatorios/>. Acesso em: 25 out.2019.

RAMIRES, J. C. de L. Os serviços de saúde de alta complexidade em Uberlândia e Uberaba: contribuições para a geografia urbana das cidades médias. In: RAMIRES, Júlio César de Lima (Org.). Dinâmica socioespacial e saúde coletiva em cidades de Minas Gerais. Rio de Janeiro: Carta Capital, 2013.

RODRIGUES, M.L. Espaço e serviços de saúde pública em Uberlândia (MG): uma análise do acesso ao Programa Saúde da Família Núcleo Pampulha (Dissertação - Mestrado). Universidade Federal de Uberlândia, Programa de Pós-graduação em Geografia, 2007.

SANTOS, M. Alguns Problemas Atuais da Contribuição Marxista a Geografia. In: SANTOS, M. (org). Novos rumos da geografia brasileira. São Paulo: Hucitec, 1982. p. 131-139.

SANTOS, M. Espaço e Método. São Paulo: Nobel, 1985.

SANTOS, M. Manual de Geografia Urbana. 3. ed. São Paulo: Editora da Universidade de São Paulo, 2008.

SILVA, M.R. Olhar periférico Análise da paisagem urbana de Jataí (GO) período de 2008 a 2018. In.: MARTINS, Alécio Perini; CABRAL, João Batista Pereira (Orgs.). Reflexões Geográficas no Cerrado Brasileiro. vol. I. Curitiba: Editora CRV, 2019.

\begin{tabular}{lllll}
\hline Hygeia & Uberlândia - MG & Edição especial: X GeoSaude & Fev./2022 & p. 120-135 Página 134
\end{tabular}


SOUZA, M.C. ABC do desenvolvimento urbano. Rio de Janeiro: Bertrand Brasil, 2003.

VIEGAS, A.P.B.; CARMO, R.F.; LUZ, Z.M.P. Fatores que influenciam o acesso aos serviços de saúde na visão de profissionais e usuários de uma unidade básica de referência. Saúde e Sociedade, São Paulo, v. 24, n. 1, p. 100-112, mar. 2015. https://doi.org/10.1590/S0104-12902015000100008 